\title{
The Prevalence and Types of Gambling Among Undocumented Mexican Immigrants in New York City
}

\author{
Sandra L. Momper • Vijay Nandi · Danielle C. Ompad · Jorge Delva • \\ Sandro Galea
}

(C) Springer Science+Business Media, LLC 2008

\begin{abstract}
Objectives To examine the prevalence of gambling and types of gambling activities in a sample of undocumented Mexican immigrants. Design Non-probability cross-sectional design. Setting New York City. Sample The 431 respondents ranged in age from 18 to 80 (mean age 32), 69.7\% were male. Results More than half (53.8\%) reported gambling in their lifetime and of those most (43.9\%) played scratch and win tickets or the lottery. In multivariate analyses men reported gambling more than women $[2.13,95 \%$ $\mathrm{CI}=(1.03,4.38)]$. The odds of gambling in their lifetime were higher among those reporting sending money to family or friends in the home country $[2.65,95 \% \mathrm{CI}=1.10$, 6.38)], and those who reported 1-5 days as compared to no days of poor mental health in the past 30 days $[2.44,95 \% \mathrm{CI}=1.22,4.89)]$. Conversely, those who reported entering the U.S. to live after 1996 were less likely to report gambling [0.44, 95\% CI $=(0.22$, 0.89)] as compared to those who had lived in the U.S. longer. Conclusion There is a need to further explore both the prevalence and the severity of gambling amongst the growing population of undocumented Mexican immigrants in the U.S.
\end{abstract}

Keywords Undocumented Mexicans - Illegal immigrants · Minorities · Prevalence and types of gambling · Problem gambling

S. L. Momper $(\bowtie) \cdot$ J. Delva

School of Social Work, University of Michigan,

1080 South University Avenue, Ann Arbor, MI 48109, USA

e-mail: smomper@umich.edu

V. Nandi · D. C. Ompad

Center for Urban Epidemiologic Studies, New York Academy of Medicine,

New York, NY 10029, USA

J. Delva

Institute for Social Research, University of Michigan, Ann Arbor, MI 48109, USA

S. Galea

Center for Social Epidemiology and Population Health, Department of Epidemiology,

School of Public Health, Survey Research Center, Institute for Social Research,

University of Michigan, Ann Arbor, MI 48109, USA 


\section{Introduction}

The prevalence of problem or pathological gambling appears to be greater among racial/ ethnic minorities than it is among whites in the United States (U.S.) (Murray 1993; Raylu and Oei 2004; Volberg 1994, 1996; Wardman et al. 2001). However, there is a paucity of research about gambling behaviors among minority groups, specifically undocumented and lower socioeconomic status (SES) populations. The lack of knowledge about gambling behaviors among minority groups in general, and undocumented groups, specifically, and especially those of lower SES, is of concern given that these populations may be at higher risk of experiencing problem or pathological gambling disorders (Cunningham-Williams et al. 2007; Welte et al. 2004b). Minorities of lower SES are at greater risk of developing gambling problems as it is believed that the increased availability of gambling venues in low SES areas has led to a shift in the demographics of gamblers, who were traditionally high SES White males, to low SES gamblers and minorities who now view gambling as entertainment, a way to win money quickly, and thereby may be at risk of developing more gambling problems (Gill et al. 2006; Welte et al. 2002). Studies are needed to investigate how undocumented Mexican immigrants are affected by this shift in gambling demographics. To date no studies exist that specifically study the gambling behaviors of undocumented Mexican immigrants. Undocumented immigrants are a vulnerable, and understudied, minority population that may be at higher risk of experiencing gambling problems given their immigration status and low SES. One study of Anglo and Hispanic callers to a Gambling Hotline noted a marked difference in calls for assistance between the groups (96.2\% Anglo and 3.8\% Hispanic) (Cuadrado 1999). Another study of older and younger adult problem gamblers found that the younger adult group had more Hispanic and "other" problem gamblers and fewer Caucasian problem gamblers (Potenza et al. 2006a). Westermeyer et al. 2005 found that among Hispanic American veterans lifetime pathological gambling rates were $1 \%$ higher than general population samples $(4.3 \%)$. None of the studies specifically noted nativities or immigration status. Studies that specifically look at the gambling practices among undocumented Mexicans are non-existent and are further challenged by the difficulties of accessing and identifying undocumented Mexican immigrants.

There has been a 30\% increase in undocumented individuals in the U.S. since $2000(8.4$ million to 11 million) (Passel 2005). Six million of these undocumented individuals are Mexican. Extant research suggests that undocumented immigrants may be at greater risk of disease and injury than documented immigrants and native-born populations (Loue and Mendez 2005), making this group of high interest from a population health point of view. Gambling, especially excessive gambling behaviors are associated with diminished health related quality of life. (Scherrer et al. 2005). However, to date no studies exist that specifically study the gambling behaviors of undocumented Mexicans resulting in an important gap in our understanding of the extent of gambling, gambling-related problems, and service needs in this vulnerable population.

To contribute to the understanding of gambling behaviors among undocumented immigrants, findings are presented from a larger study of Mexicans living in New York City (NYC), where the foreign born Mexican population increased by $275 \%$ between 1990 and 2000 (The Newest New Yorkers 2004). The objectives of this analysis were to: (1) estimate the prevalence of gambling in a sample of undocumented Mexican immigrants; (2) examine the extent to which demographic, social, economic, and cultural variables are associated with gambling; and (3) examine the types of gambling activities that undocumented Mexican immigrants are engaged in. 


\section{Methods}

\section{Subjects and Study Design}

The data for the current analyses are drawn from a larger 2004 study of 505 persons who were born in Mexico but were living in New York City (NYC) (see Nandi et al. 2008; Hadley et al. 2008). For this particular study, the sample is restricted to the 431 respondents who reported undocumented immigration status. The purpose of the larger study was to conduct a comprehensive assessment of the determinants of access to and utilization of health services among undocumented Mexican immigrants living in NYC. We utilized venue based sampling and the sampling frame consisted of adults (age 18 and older) from five boroughs of NYC who reported being born in Mexico. Specifically, participants (age 18 years and older) were recruited from venues in NYC communities with large populations of Mexican immigrants. Venues were selected using a two phase procedure. In phase one; data were used from the 2000 U.S. Census to identify the 12 neighborhoods in NYC, as defined by the NYC Department of Planning, with the highest reported clusters of Mexican immigrants (U.S. Census 2003; The Newest New Yorkers 2004). The neighborhoods were Sunset Park, East Harlem, North Corona, Elmhurst, Jackson Heights, Astoria, Bushwick, Williamsburg, South Bronx, Chelsea, Lower East Side and Port Richmond. In phase two, a systematic assessment of all the streets in the 12 neighborhoods was conducted on differing days and times to identify busy neighborhood venues that would be receptive to conducting interviews. For the present study, only illegal residents were included in analyses.

Outreach workers trained in data collection methods recruited participants between October 8, 2004 and December 5, 2004 using outreach techniques that have been utilized extensively in research on immigrant populations (Loue et al. 2000; Marshall et al. 2005) and other hard to access populations (Anthony et al. 1991; Vlahov et al. 1991). For example, the workers distributed flyers about the study at the venues and engaged interested potential participants in conversations about the objectives, the criteria for inclusion, and the voluntary and anonymous nature of the study.

Eligible participants were 18 years of age or older, self-reported to be Mexican, not born in the U.S., and current residents of NYC. If interested the participants later returned and participated in a 20 minute interview in English (less than 2\%) or Spanish with translated and back-translated structured questionnaires. Institutional Review Board approval was received at the New York Academy of Medicine and New York University. To preserve anonymity oral consent was obtained and no identifying information was collected.

\section{Measures}

An adapted version of the South Oaks Gambling Screen (SOGS) (LeSieur and Blume 1987) was used to estimate prevalence of gambling behaviors and types of gambling activities. Due to space limitations, given that the gambling questions were part of a larger study/survey, only 7 of the 20 SOGS items were included in the study. Lifetime prevalence was assessed by asking the respondent if he/she had ever undertaken any of the following types of gambling: (1) "played scratch and win tickets or the lottery," (2) "played card games for money," (3) "played dice games for money," (4) "played pool or darts for money," (5) "bet money on horse races, dog fights, or cockfights," and (6) "bet money on 
sports, bingo, or going to a casino." If they responded "Yes" to any of the items, respondents were asked an additional question to assess how often they participated in this type of gambling in the past six months [Response options were 1 (not at all), 2 (less than once a week) and 3 (once a week or more)]. The seventh question was as follows: "What is the largest amount of money you have ever gambled with on any one day?" [Response options ranged from 1 (never have gambled) to 7 (more than \$10,000)].

Socio-demographic characteristics included age (18-24, 25-34, 35-44, and greater than 44 years of age); gender (male or female); educational attainment (less than high school, high school diploma or equivalent, and at least some college); marital status (single, married, divorced, and other); and residency status. Respondents were asked if they were a legal resident of the U.S. and what year they first entered the U.S. to live. In analyses, to reflect the changes in U.S. legislation that took place in 1996, we dichotomized the year of entry as before or after January 1, 1997 (Kullgren 2003). In 1996, the Personal Responsibility Work Opportunity Reconciliation Act of 1996 (PRWORA) was passed by Congress. One of the objectives of this legislation was to restrict federal, state, and local public services among undocumented immigrants (Kullgren).

We asked respondents about social and economic factors. To assess social support we included 5 items from the Medical Outcomes Study (MOS) social support survey (Sherbourne and Stewart 1991). We asked about tangible support (e.g., "someone available to help you if you were confined to bed"), emotional support (e.g., "someone available to give you good advice about a crisis", and "someone available to confide in or talk to about your problems"), positive social interaction (e.g., "someone available to get together for relaxation"), and affectionate support (e.g., "someone available to love you and make you feel wanted") [Response options ranged from 1 (none of the time) to 4 (all of the time)]. Responses were summed and divided into categories for analysis: none/low, medium and high social support. We asked respondents to report on their economic situation by asking about their 'legal income' (i.e., "on the books" taxed income, including public assistance), and 'off the books' income (i.e., non-taxed income). We categorized both sources of income into 3 categories: no income, $\$ 1-\$ 9,999$, and greater than $\$ 10,000$. In addition respondents were asked if they received money from social services in the past 6 months.

Levels of linguistic and social acculturation were assessed using an adapted version of the twelve item Welfare Reform Baseline Interview acculturation module, developed specifically for Hispanic peoples (Marin et al. 1987). Linguistic acculturation was assessed using seven items that asked about the preference for other languages when compared to English (e. g., "what was the language you used as a child?"). Respondents indicated on a on a 5-point scale ranging from 1 (Only English) to 5 (Only Not English). Responses were reverse coded so that higher scores indicated a preference for English. Social acculturation was assessed with four items that asked about preference for Mexican, Latino, or Hispanic groups as compared to other groups in different social milieu (e.g., "you prefer going to social gatherings/parties where people are...?"). Response categories for each item were on a 5-point scale ranging from 1 (Almost all Mexican, Latino, Hispanic) to 5 (Almost all not Mexican, Latino, Hispanic). Higher scores indicated a preference for interaction with "almost all not Mexicans, Latinos, and Hispanics." The scores of linguistic and social acculturation were summed and categorized into 3 categories of acculturation: lowest, moderate, and highest. In this study the Cronbach's alpha for items used in both scales was 0.92 .

We measured overall health, physical, and mental health with 3 items. Respondents rated their overall health (excellent, very good, good, fair, or poor), and then their perception of their physical health in the past 30 days, specifically how many days ( 0 days, 
1-5 days, greater than 5 days) they viewed their health as 'not good', and then respondents rated their mental health using the 30 days indicator and the 'not good' categories as well. These 3 measures have been reported to be valid and reliable (Andresen et al. 2000, 2003).

\section{Statistical Analyses}

To measure prevalence of gambling we calculated the number and percentage of respondents who reported "Yes" to any of the types of gambling. Spearman's correlation and Chi Square tests were used to measure bivariate associations between the study variables. We used multivariate logistic regression models to identify variables independently associated with having ever gambled. For covariates included in the model see Table 1. Multivariate analyses were conducted with predictor variables that were significantly associated with the dependent variable at a significance level of $<0.2$ in the bivariate tests. Odds ratios were tested for significance using a two-tailed Wald chi-square test whose null hypothesis is that the odds ratio is equal to one, or no association. SAS software version 9.1 (SAS Institute, Cary, NC) was used for all statistical analyses.

\section{Results}

A total of 431 individuals indicated undocumented status. Of those, the majority had lived in the U.S. for less than 10 years $(65 \%)$. Respondents ranged in age from 18 to 80 , with a mean age of $31.7(\mathrm{SD}=9.0)$, and $69.7 \%$ were male. Eighty-three percent of the respondents reported less than a high school education, $10 \%$ having a high school diploma or equivalent, and $7 \%$ some college. Half of the sample was married, $41 \%$ were single, $1.7 \%$ were divorced, and $7.3 \%$ were in an 'other' category. Yearly legal income of between $\$ 1$ and 1 and $\$ 10,000$ was reported by $16 \%$ of the respondents, and $12 \%$ reported income of more than $\$ 10,000$. In the 'legal' income category $57 \%$ of the respondents reported no income and missing responses were $15 \%$. For the 'off the books' income, $31 \%$ had income between $\$ 1$ and $\$ 10,000,21 \%$ had income of more than $\$ 10,000,26 \%$ reported no income, and $22 \%$ did not respond. In the past 6 months $24 \%$ of the respondents reported working as a day laborer. A large percentage $(85 \%)$ of the respondents reported sending money to their home country to family and friends. Of the total sample $53.8 \%$ were gamblers $(N=232)$ and $46.2 \%$ were non-gamblers $(N=199)$ (Table 1). When compared to non-gamblers, a greater percent of gamblers were male, had legal incomes greater than $\$ 10,000$, lived in the U.S. longer, had not received money from social services in the past 6 months, had sent more money to family and friends in the home country, had higher levels of linguistic and social acculturation, and reported more days of poor physical and mental health.

Of the respondents who reported gambling in their lifetime, the largest percentage of gambling activity engaged in ever in their lifetime was scratch and win tickets or the lottery (43.9\%) (Table 2). Interestingly, among those who reported gambling, $46.1 \%$ did not gamble on any of the activities in the past 6 months, 38.4\% gambled on 1 activity, $11.2 \%$ gambled on 2 activities, $2.6 \%$ gambled on 3 activities and $1.9 \%$ gambled on 4 activities. For gamblers the amount of money they gambled in one day was $\$ 1-\$ 10$ $(19.8 \%), \$ 10-\$ 100(15.6 \%), \$ 1$ or less $(7.2 \%), \$ 100-\$ 1,000(6.2 \%)$, and over $\$ 1,000$ $(0.8 \%)$. Of those who reported playing scratch and win tickets or the lottery, $44.7 \%$ 
Table 1 Socio-demographic characteristics and bivariate associations between covariates of interest and lifetime gamblers and non-gamblers among undocumented Mexican immigrants of NYC $(N=431)$

\begin{tabular}{|c|c|c|c|c|}
\hline Variable & $N$ & $\begin{array}{l}\text { Lifetime } \\
\text { gambling, \% } \\
N=232 \\
(53.8 \%)\end{array}$ & $\begin{array}{l}\text { Lifetime } \\
\text { non-gambling, \% } \\
N=199 \\
(46.2 \%)\end{array}$ & $\chi^{2}(\mathrm{df})$ \\
\hline
\end{tabular}

Legal income

$7.28 *(2)$

$\begin{array}{lrrr}\text { No income } & 246 & 65.7 & 68.8 \\ \$ 1-10,000 & 70 & 16.4 & 22.5 \\ >10 \mathrm{~K} & 51 & 17.9 & 8.8\end{array}$

Off the books

No income
$\$ 1-10,000$
$>10 \mathrm{~K}$

Age categories

$18-24$

25-34

$35-44$

$>44$

Gender

Female

Marital status

Single

Married

Divorced

Other

Years in the USA-categories

1978-1991

1992-1996

1997-1999

2000-2001

$>2001$

112

$91 \quad 31.6$

Year entered USA

1996 or earlier

After 1996

Worked as day laborer

(past 6 months)

Yes

No

Social support

Low

Medium

High

Last 6 months, received money from social services

$\begin{array}{lrrr}\text { Yes } & 39 & 6.0 & 12.6 \\ \text { No } & 392 & 94.0 & 87.4\end{array}$

30.1

$135 \quad 38.3$

104

26.3

177

112

39.2

25.4

9.1

130

22.4

177

44.0

218

47.0

1.7

7.3

27

78

23.0

64

16.5

88

17.4

17.8

25.2

80

108

142

39.6

276

60.4

103

328

24.6

37.3

42.3

20.4

1.58 (3)

21.7

43.4

26.8

8.1

39.6

$14.89 * * *(1)$

$3.54(3)$

37.7

54.8

2.5

5.0

13.3

13.8

25.5

20.7

26.6

27.1

72.9

0.12 (1)

$7.13^{* *}(1)$

$187 \quad 43.8$

1.27 (2)

48.1

37.3

14.6

$5.55^{*}(1)$ 
Table 1 continued

\begin{tabular}{|c|c|c|c|c|}
\hline Variable & $N$ & $\begin{array}{l}\text { Lifetime } \\
\text { gambling, \% } \\
N=232 \\
(53.8 \%)\end{array}$ & $\begin{array}{l}\text { Lifetime } \\
\text { non-gambling, \% } \\
N=199 \\
(46.2 \%)\end{array}$ & $\chi^{2}(\mathrm{df})$ \\
\hline $\begin{array}{l}\text { Send money to family/friends } \\
\text { in home country }\end{array}$ & & & & $13.53^{* * *}(1)$ \\
\hline Yes & 366 & 91.0 & 78.3 & \\
\hline No & 64 & 9.1 & 21.7 & \\
\hline $\begin{array}{l}\text { Education (highest level } \\
\text { completed) }\end{array}$ & & & & $2.68(2)$ \\
\hline Less than high school & 358 & 80.6 & 85.9 & \\
\hline High school or GED & 43 & 10.8 & 9.1 & \\
\hline At least some college & 30 & 8.6 & 5.0 & \\
\hline Linguistic acculturation/preference & & & & $19.54 * * *(2)$ \\
\hline Lowest level of acculturation & 106 & 19.5 & 35.1 & \\
\hline Moderate acculturation & 122 & 28.6 & 33.5 & \\
\hline Highest level of acculturation & 167 & 51.9 & 31.4 & \\
\hline Social acculturation/preference & & & & $22.16^{* * *}(2)$ \\
\hline Lowest level of acculturation & 172 & 32.7 & 56.3 & \\
\hline Moderate acculturation & 106 & 32.2 & 20.8 & \\
\hline Highest level of acculturation & 116 & 35.1 & 23.0 & \\
\hline Overall health & & & & $3.75(4)$ \\
\hline Excellent & 46 & 10.8 & 10.6 & \\
\hline Very good & 64 & 13.8 & 16.2 & \\
\hline Good & 192 & 42.7 & 47.0 & \\
\hline Fair & 99 & 24.1 & 21.7 & \\
\hline Poor & 29 & 8.6 & 4.6 & \\
\hline Poor mental health & & & & $19.19 * * *(2)$ \\
\hline 0 days & 227 & 43.9 & 64.8 & \\
\hline $1-5$ days & 119 & 35.1 & 19.9 & \\
\hline$>5$ days & 78 & 21.1 & 15.3 & \\
\hline Poor physical health & & & & $10.06 * *(2)$ \\
\hline 0 days & 253 & 52.6 & 67.7 & \\
\hline $1-5$ days & 101 & 28.3 & 18.5 & \\
\hline$>5$ days & 71 & 19.1 & 13.9 & \\
\hline
\end{tabular}

$* P<0.05, * * P<0.01, * * * P<0.001$

gambled $\$ 1-\$ 10$ and $24.3 \%$ gambled $\$ 10-\$ 100$. A total of $51 \%$ of respondents never gambled any amount of money.

The bivariate analyses of associations between types of gambling activities and the variables of interest (age, gender, income source and acculturation levels) are presented in Table 3. Gamblers who played scratch and win tickets or the lottery, card games or pool or darts for money, bet on horse races, dog, or cockfights, and bet on sports, bingo, or in a casino, were overwhelmingly male. Scratch and win tickets or lottery players had higher legal incomes and those who bet on sports, bingo, or in a casino had higher levels of linguistic acculturation. Playing dice games for money revealed no associations. 
Table 2 Prevalence of types of gambling activities $(N=431)$

\begin{tabular}{|c|c|c|c|c|c|c|c|c|}
\hline \multirow[t]{3}{*}{ Types of gambling (lifetime) } & \multirow[t]{3}{*}{$N$} & \multirow[t]{3}{*}{$\%$} & \multicolumn{6}{|c|}{ How often played in last 6 months } \\
\hline & & & \multicolumn{2}{|c|}{ Not at all } & \multicolumn{2}{|c|}{$\begin{array}{l}<\text { Once } \\
\text { a week }\end{array}$} & \multicolumn{2}{|c|}{$\begin{array}{l}\text { Once a week } \\
\text { or more }\end{array}$} \\
\hline & & & $N$ & $\%$ & $N$ & $\%$ & $N$ & $\%$ \\
\hline \multicolumn{9}{|l|}{ Scratch $\mathrm{n}$ win tickets/lottery } \\
\hline No & 242 & 56.2 & & & & & & \\
\hline Yes & 189 & 43.9 & 37 & 19.7 & 80 & 42.6 & 71 & 37.8 \\
\hline \multicolumn{9}{|l|}{ Played card games for money } \\
\hline No & 388 & 90.2 & & & & & & \\
\hline Yes & 42 & 9.8 & 13 & 37.1 & 21 & 60.0 & 1 & 2.9 \\
\hline \multicolumn{9}{|l|}{ Played dice games for money } \\
\hline No & 424 & 98.8 & & & & & & \\
\hline Yes & 5 & 1.2 & 2 & 40.0 & 1 & 20.0 & 2 & 40.0 \\
\hline \multicolumn{9}{|l|}{ Played pool or darts for money } \\
\hline No & 411 & 95.6 & & & & & & \\
\hline Yes & 19 & 4.4 & 2 & 11.1 & 9 & 50.0 & 7 & 38.9 \\
\hline \multicolumn{9}{|c|}{ Bet on horse races, dog or cock fights } \\
\hline No & 414 & 96.1 & & & & & & \\
\hline Yes & 17 & 4.0 & 10 & 62.5 & 4 & 25.0 & 2 & 12.5 \\
\hline \multicolumn{9}{|c|}{ Other betting (sports, bingo, casino) } \\
\hline No & 374 & 87.4 & & & & & & \\
\hline Yes & 54 & 12.6 & 11 & 20.8 & 34 & 64.2 & 8 & 15.1 \\
\hline \multicolumn{9}{|c|}{ Largest amount gambled in one day } \\
\hline Have never gambled & $205^{\mathrm{a}}$ & 50.6 & & & & & & \\
\hline$\$ 1$ or less & 29 & 7.2 & & & & & & \\
\hline$>\$ 1$ up to $\$ 10$ & 80 & 19.8 & & & & & & \\
\hline$>\$ 10$ up to $\$ 100$ & 63 & 15.6 & & & & & & \\
\hline$>\$ 100$ up to a $\$ 1,000$ & 25 & 6.2 & & & & & & \\
\hline$>\$ 1,000$ up to $\$ 10,000$ & 2 & 0.5 & & & & & & \\
\hline$>\$ 10,000$ & 1 & 0.3 & & & & & & \\
\hline
\end{tabular}

${ }^{a}$ In Table 1 the $N$ for non-gamblers is 199 . In this table 205 participants reported not gambling. This may be due to the sensitive nature of the question regarding money

Findings from the multiple logistic regression analyses indicated that gender, year entered the U.S. to live, sending money to family and friends in the home country, and reporting poor mental health from 1 to 5 days in the past 30 days, were all associated with reports of lifetime gambling (Table 4). Specifically, men were more likely to report gambling than women $[2.13,95 \% \mathrm{CI}=(1.03,4.38)]$. The odds of gambling were higher among those reporting sending money to family and friends in the home country [2.65, $95 \% \mathrm{CI}=1.10,6.38)]$ and those who reported $1-5$ days as compared to no days of poor mental health in the past 30 days $[2.44,95 \% \mathrm{CI}=1.22,4.89)]$. Conversely, those who reported entering the U.S. to live after 1996 were less likely to report gambling [0.44, 95\% $\mathrm{CI}=(0.22,0.89)]$ when compared to those who entered in 1996 or earlier. 


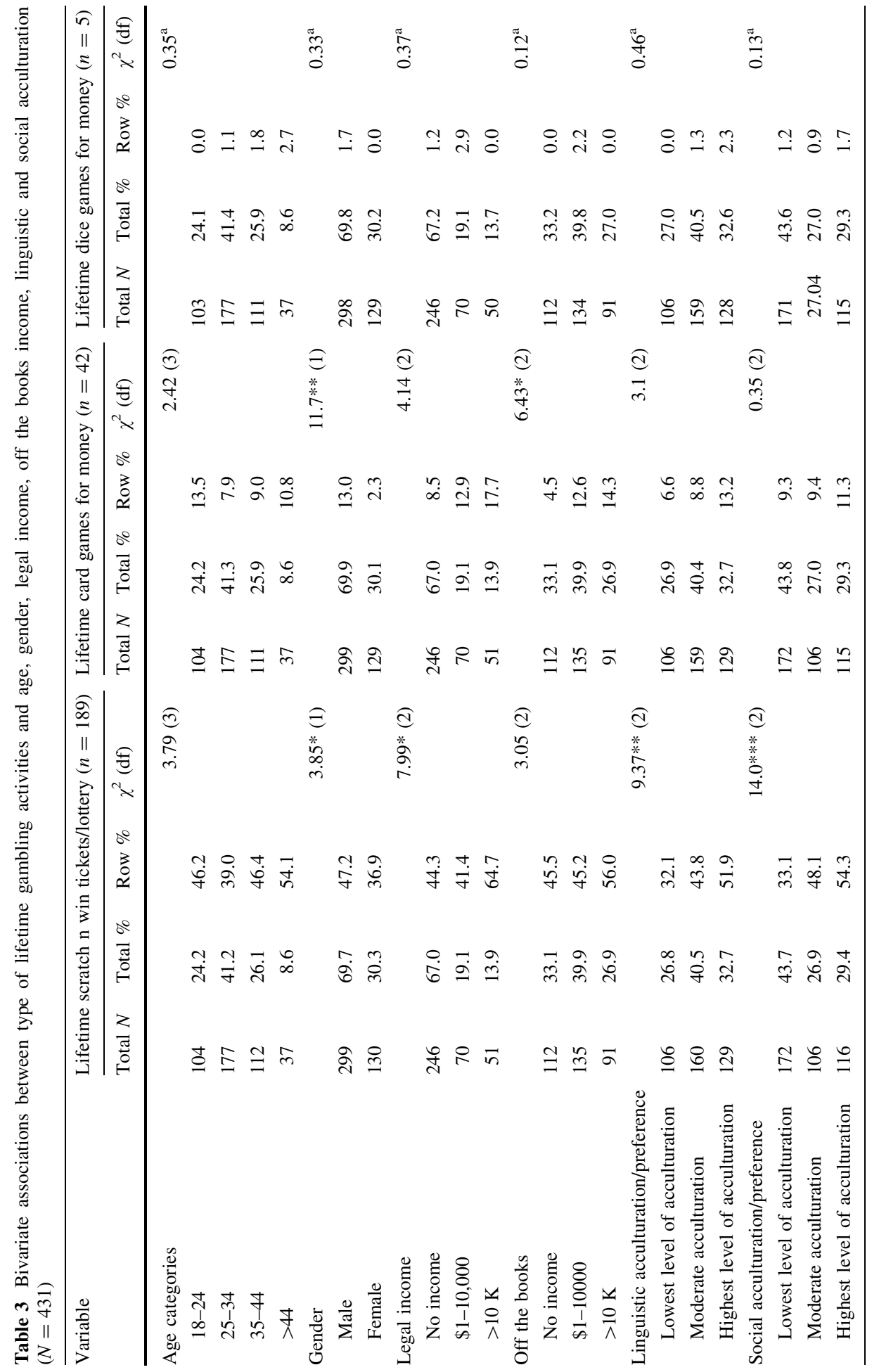




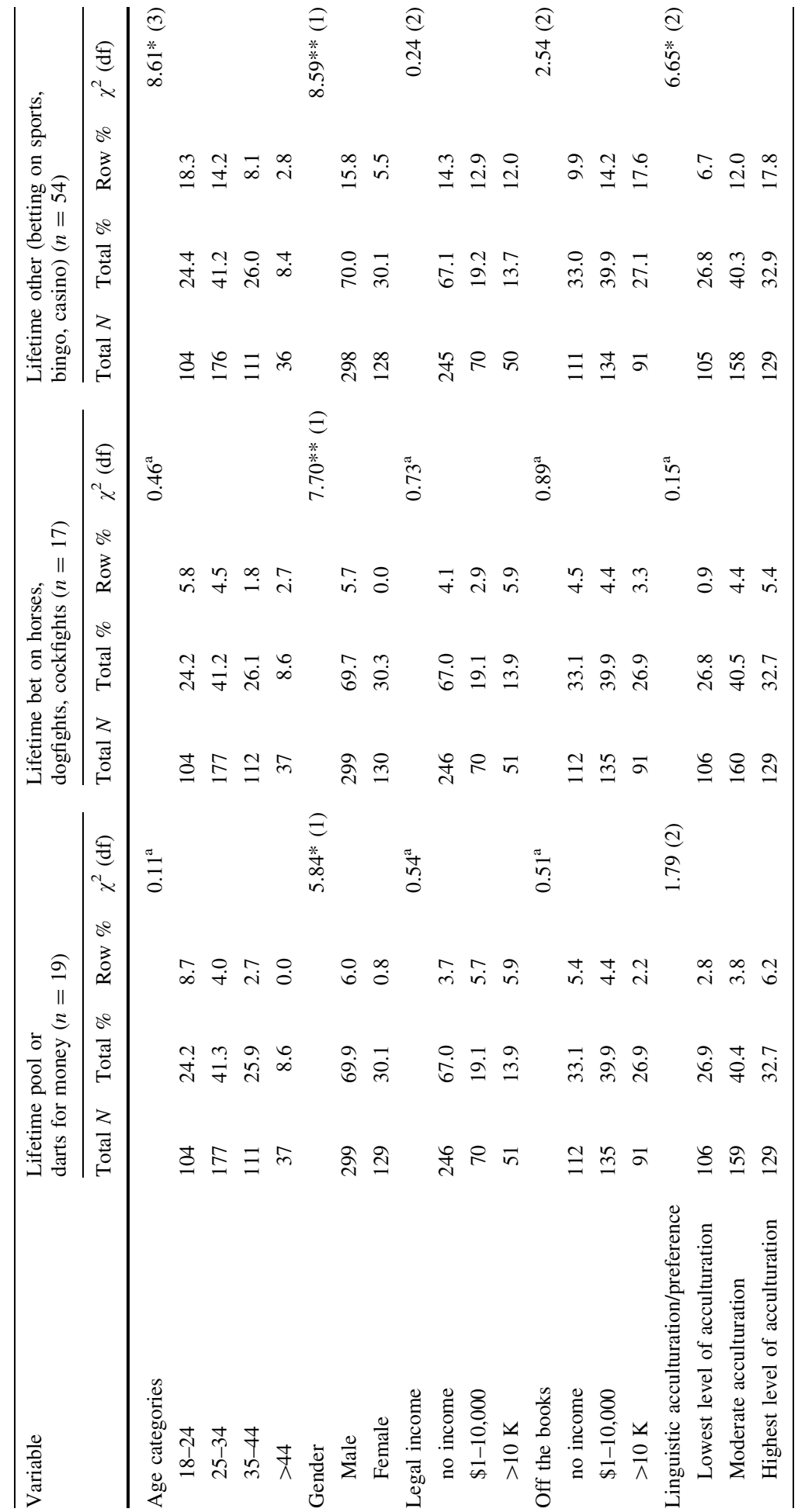




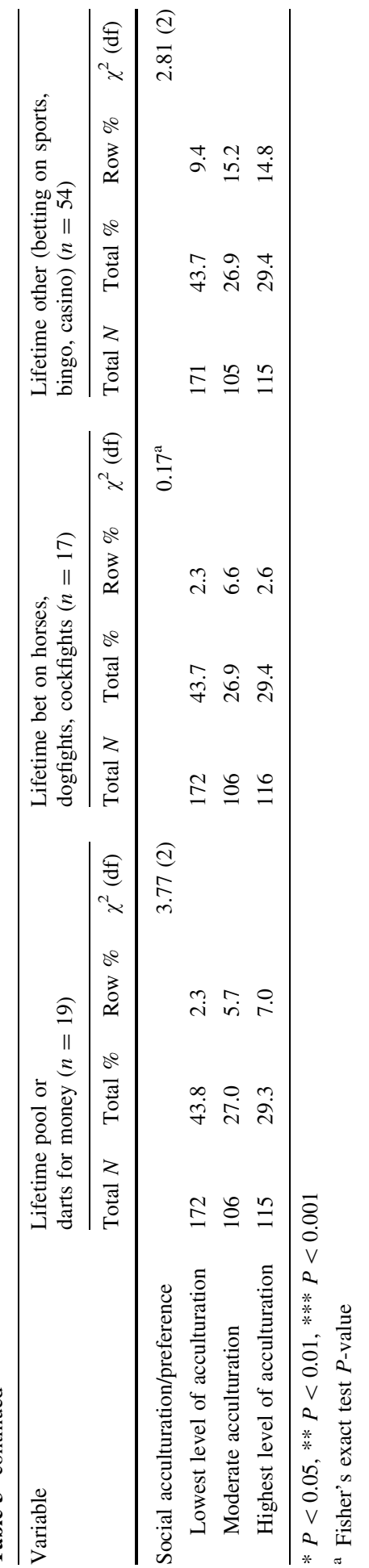


Table 4 Multivariable associations between social, economic and cultural variables and lifetime prevalence of any gambling $(N=232)$

\begin{tabular}{|c|c|c|}
\hline Variable & Adjusted O.R. (95\% CI) & Adjusted $^{\mathrm{a}}$ O.R. $(95 \% \mathrm{CI})$ \\
\hline \multicolumn{3}{|l|}{ Legal income } \\
\hline No income & Referent & Referent \\
\hline$\$ 1-10,000$ & $0.86(0.36-2.08)$ & $0.82(0.37-1.83)$ \\
\hline$>10 \mathrm{~K}$ & $1.55(0.54-4.44)$ & $1.45(0.55-3.84)$ \\
\hline \multicolumn{3}{|l|}{ Off the books } \\
\hline No income & Referent & Referent \\
\hline$\$ 1-10,000$ & $0.84(0.39-1.84)$ & $0.79(0.39-1.61)$ \\
\hline$>10 \mathrm{~K}$ & $1.04(0.42-2.58)$ & $1.06(0.46-2.46)$ \\
\hline \multicolumn{3}{|l|}{ Age categories } \\
\hline $18-24$ & Referent & \\
\hline $25-34$ & $0.54(0.24-1.20)$ & \\
\hline $35-44$ & $0.39(0.15-1.06)$ & \\
\hline$>44$ & $0.75(0.20-2.91)$ & \\
\hline \multicolumn{3}{|l|}{ Gender } \\
\hline Male & $1.95(0.85-4.46)$ & $2.13 *(1.03-4.38)$ \\
\hline Female & Referent & Referent \\
\hline \multicolumn{3}{|l|}{ Marital status } \\
\hline Single & Referent & \\
\hline Married & $1.32(0.65-2.67)$ & \\
\hline Divorced & $1.18(0.14-10.0)$ & \\
\hline Other & $1.16(0.26-5.18)$ & \\
\hline \multicolumn{3}{|l|}{ Year entered USA } \\
\hline 1996 or earlier & Referent & Referent \\
\hline After 1996 & $0.32 * *(0.14-0.73)$ & $0.44 *(0.22-0.89)$ \\
\hline \multicolumn{3}{|c|}{ Worked as day laborer (past 6 months) } \\
\hline Yes & $1.00(0.46-2.15)$ & \\
\hline No & Referent & \\
\hline \multicolumn{3}{|l|}{ Social support } \\
\hline Low & Referent & \\
\hline Medium & $0.84(0.42-1.68)$ & \\
\hline High & $0.66(0.27-1.61)$ & \\
\hline \multicolumn{3}{|c|}{ Last 6 months, received money from social services } \\
\hline Yes & $0.621(0.20-1.94)$ & $0.82(0.28-2.41)$ \\
\hline No & Referent & Referent \\
\hline \multicolumn{3}{|c|}{ Send money to family/friends in home country } \\
\hline No & Referent & Referent \\
\hline Yes & $2.54(0.95-6.79)$ & $2.65^{*}(1.10-6.38)$ \\
\hline \multicolumn{3}{|c|}{ Education (highest level completed) } \\
\hline Less than high school & $1.39(0.50-3.86)$ & \\
\hline High school or GED & Referent & \\
\hline At least some college & $1.97(0.45-8.69)$ & \\
\hline
\end{tabular}


Table 4 continued

\begin{tabular}{|c|c|c|}
\hline Variable & $\begin{array}{l}\text { Adjusted O.R. } \\
(95 \% \mathrm{CI})\end{array}$ & $\begin{array}{l}\text { Adjusted O.R. }(95 \% \mathrm{CI}) \\
\text { Model with variables }<0.2 \\
\text { significance level in bivariate }\end{array}$ \\
\hline \multicolumn{3}{|l|}{ Linguistic acculturation/preference } \\
\hline Lowest level of acculturation & Referent & Referent \\
\hline Moderate acculturation & $0.76(0.34-1.74)$ & $0.89(0.41-1.91)$ \\
\hline Highest level of acculturation & $1.52(0.64-3.61)$ & $1.58(0.73-3.45)$ \\
\hline \multicolumn{3}{|l|}{ Social acculturation/preference } \\
\hline Lowest level of acculturation & Referent & Referent \\
\hline Moderate acculturation & $2.02(0.92-4.43)$ & $1.97(0.94-4.13)$ \\
\hline Highest level of acculturation & $1.89(0.88-4.03)$ & $1.86(0.91-3.79)$ \\
\hline \multicolumn{3}{|l|}{ Overall health } \\
\hline Excellent & Referent & \\
\hline Very good & $1.08(0.30-3.90)$ & \\
\hline Good & $0.68(0.23-2.02)$ & \\
\hline Fair & $0.36(0.07-1.98)$ & \\
\hline Poor & $0.54(0.17-1.76)$ & \\
\hline \multicolumn{3}{|l|}{ Poor mental health } \\
\hline 0 days & Referent & Referent \\
\hline $1-5$ days & $2.59 *(1.22-5.53)$ & $2.44 *(1.22-4.89)$ \\
\hline$>5$ days & $1.38(0.58-3.30)$ & $1.34(0.59-3.03)$ \\
\hline \multicolumn{3}{|l|}{ Poor physical health } \\
\hline 0 days & Referent & Referent \\
\hline $1-5$ days & $1.18(0.53-2.63)$ & $1.12(0.55-2.29)$ \\
\hline$>5$ days & $1.96(0.75-5.14)$ & $2.01(0.87-4.63)$ \\
\hline
\end{tabular}

$* P<0.05, * * P<0.01$, *** $P<0.001$

${ }^{a}$ The adjusted analyses include predictor variables that in the bivariate analyses were significantly associated with the dependent variable with $P<0.2$

\section{Discussion}

To the best of our knowledge, this is the first study to examine characteristics of gambling among undocumented Mexican immigrants. This demographic group is rapidly growing in both size and social importance in the U.S. and little detailed information exists. When considering the entire sample, we found that the lifetime prevalence of gambling among immigrants $(53.8 \%)$ was not too dissimilar from that estimated in general population samples of recreational gamblers (60\%) (Gerstein et al. 1999; Potenza et al. 2002; Welte et al. 2004a). However, in our study the percent of men who gamble (78\%) is considerably larger than the percent of women who gamble (22\%) when compared to the percent of men and women estimated to gamble in the general population (66.\% vs. 59.3\%, respectively) (Gerstein et al. 1999; Potenza et al. 2006b). It is possible that the gender differences in gambling observed in our study reflect gambling behaviors of Mexicans in Mexico. We are unable to confirm this as data on the extent of gambling in Mexico is non-existent and gambling in Mexico is limited to pari-mutuel or Class II gaming (Gambling in Mexico 2008). However, in a U.S. study of Hispanics (nativities not noted) Cuadrado (1999) reports that differences between Hispanic men and women in regard to calls for help to a 
gambling hotline (men call less) and gambling prevalence (men gamble more) may be attributed to cultural norms of marianismo and machismo that promote or serve to enforce certain behavioral expectations for the men and women. Marianismo refers to the enforcement of traditional gender roles among Mexican women including but not limited to their being dependent and subordinate to men and being responsible for domestic chores and the care of children (Arciniega et al. 2004). The concept of marianismo is the opposite of the concept of machismo. The latter encourages men to also follow stereotypical gender roles whereby men's' involvement in risk-taking behaviors, such as gambling, is not only tolerated but encouraged as part of what it means to be a 'man'. In U.S. gambling studies of recreational gamblers (as in the current study) men are more likely to engage in gambling for "excitement" and women for "escape" (Pantalon et al. 2008; Trevorrow and Moore 1998). In U.S. studies of problem and pathological gamblers men gamble about two times more than women (Gerstein et al. 1999; Volberg 2001, 2003). Certainly, more research is needed to understand the cultural aspects of gambling behaviors between men and women in general and among diverse cultural groups such as among undocumented men and women, in particular.

We found that undocumented Mexican immigrants who reported worse mental health (stress, depression, and emotional problems) were more likely to report having ever gambled although those with the worst mental health were less likely to have ever gambled. This is consistent with the findings of Kim et al. (2006) who found that depressive symptoms are common among those who engage in gambling, but not as common among pathological gamblers. However, the causal relationship between gambling and depression remains unknown. The St. Louis Epidemiologic Catchment Area Study found that problems relating to gambling occurred after periods of major depression (CunninghamWilliams et al. 1998). It is possible that people suffering from depression turn to gambling to escape from or alleviate the symptoms of the disorder. Conversely, evidence also suggests that gamblers may experience increased bouts of depressive symptoms as financial losses increase (McCormick et al. 1984; Thorson et al. 1994). Although it is clear that an association between gambling and mental health symptoms exists among Mexican immigrants, additional research is needed to untangle the temporal and causal associations between these variables.

Particular aspects of the immigrant experience were associated with gambling behaviors. Immigrants who reported having gambled in their lifetime also reported higher levels of linguistic and social acculturation. Conversely, those who reported entering the U.S. to live after 1996 (i.e. less time in the country) had reduced odds of having ever gambled. The finding that individuals who have lived in the U.S. for a longer period of time were more likely to have ever gambled is interesting for several reasons. First, greater levels of linguistic and social acculturation reflect a greater integration process into mainstream U.S. culture, a phenomena more likely to occur among individuals who have lived in the U.S. for longer periods of time, as is the case in this study. Second, this finding may be a proxy indicator for increased financial stability among those who gamble. This idea is supported by the finding that gambling was more likely to occur among the undocumented immigrants who reported higher incomes $(>\$ 10,000)$ and among those who reported sending money home to family and friends, both variables reflecting greater financial well-being. Undocumented immigrants typically send a significant proportion of their earnings back to family or friends in their home country. Annual U.S. to Mexico remittances are estimated to be $\$ 10$ billion (Marcelli and Lowell 2005). Hence, financial stability, which may increase with the number of years lived in the U.S., may in turn facilitate gambling behaviors. 
Limitations

The study findings should be considered within the following study limitations. First, we only assessed prevalence of gambling, not problem or pathological gambling. Second, the data are cross-sectional and, as such provide no basis for inferences about temporal associations and even less about causality. Third, venue based sampling techniques preclude us from calculating a response rate. However, $85 \%$ of the respondents were undocumented immigrants, leading us to believe that we were successful in recruiting the targeted study participants, though without a sampling frame of undocumented Mexican immigrants it is not possible to assess the extent to which the sample in our study is representative of the larger population of undocumented Mexican immigrants. We used data from the 2000 U.S. Census for individuals 18 years and older to compare some of the demographic characteristics of our sample to the population of Mexicans (individuals born in Mexico) living in New York City. Our sample included a larger percent of individuals ages 35 and older (35\% vs. $22 \%$ ); males (70\% vs. $61.1 \%$ ) and individuals who did not complete high school (83\% vs. 66.8\%). Interestingly, differences according to marital status are negligible. For example, in our study and the Census, the corresponding percents of never married individuals were $41 \%$ and $40.4 \%$, respectively, and of married individuals were $51 \%$ and $52.3 \%$, respectively. Further research is needed with this population to understand the extent to which the findings are generalizable to the larger population of undocumented Mexican immigrants.

This study provides early data about gambling among undocumented Mexican immigrants in New York City. The purpose of this analysis was to assess prevalence and types of gambling behaviors. A more comprehensive study of the gambling behaviors of these undocumented Mexican immigrants is needed to identify the extent to which they are engaged in recreational, problem, or pathological gambling, including identifying factors associated with pathological gambling and the personal and societal consequences of these behaviors. This information could be utilized to inform prevention and treatment of gambling problems in this very vulnerable population.

Acknowledgments Funding for this project came from the National Institutes of Health award \# DA 017642 .

\section{References}

Andresen, E. M., Catlin, T. K., Wyrwich, K. W., \& Jackson-Thompson, J. (2003). Retest reliability of surveillance questions on health related quality of life. Journal of Epidemiology and Community Health, 57(5), 339-343. doi:10.1136/jech.57.5.339.

Andresen, E. M., Fitch, C. A., McLendon, P. M., \& Meyers, A. R. (2000). Reliability and validity of disability questions for US Census 2000. American Journal of Public Health, 90(8), 1297-1299.

Anthony, J. C., Vlahov, D., Celentano, D. D., Brown, D., \& Vlahov, D. (1991). Self-report interview data for a study of HIV-1 infection among intravenous drug users: Descriptions of methods and preliminary evidence on validity. Journal of Drug Issues, 21, 735-753.

Arciniega, G. M., Tovar-Gamero, Z. G., \& Sand, J. (2004, February). Machismo and marianismo: Definitions, instrumentation, and clinical relevance. Workshop Presented at the Relevance of Assessment and Culture in Evaluation Conference, Tempe, AZ.

Cuadrado, M. (1999). A comparison of Hispanic and Anglo calls to a gambling help hotline. Journal of Gambling Studies, 15(1), 71-81. doi:10.1023/A:1023019129809.

Cunningham-Williams, R. M., Cottler, L. B., Compton, W. M., \& Spitznagel, E. L. (1998). Taking chances: Problem gamblers and mental health disorders-Results from the St. Louis epidemiologic catchment area study. American Journal of Public Health, 88(7), 1093-1096. 
Cunningham-Williams, R. M., Ostmann, E. L., Spitznagel, E. L., \& Books, S. J. (2007). Racial/ethnic variation in the reliability of DSM-IV pathological gambling disorder. The Journal of Nervous and Mental Disease, 195(7), 551-559. doi:10.1097/NMD.0b013e318093ed13.

Gambling in Mexico (2008). Retrieved March 6, 2008, from http://www.gamblingabroad.com/internationalgambling-mexico.shtml.

Gerstein, D. R., Hoffmann, J. P., Larison, C., Engelman, L., Murphy, S., Palmer, A., et al. (1999). Gambling impact and behavior study (Vol. 1999). National Opinion Research Center, University of Chicago.

Gill, T., Dal Grande, E., \& Taylor, A. W. (2006). Factors associated with gamblers: A population based cross-sectional study of south Australian adults. Journal of Gambling Studies, 22(2), 143-164. doi: 10.1007/s10899-005-9007-z.

Hadley, C., Galea, S., Nandi, V., Nandi, A., Lopez, G., Strongarone, S., et al. (2008). Hunger and health among undocumented Mexican migrants in a US urban area. Public Health Nutrition, 11(2), 151-588. doi:10.1017/S1368980007000407.

Kim, S. W., Grant, J. E., Eckert, E. D., Faris, P. L., \& Hartman, B. K. (2006). Pathological gambling and mood disorders: Clinical associations and treatment implications. Journal of Affective Disorders, 92, 109-116. doi:10.1016/j.jad.2005.12.040.

Kullgren, J. T. (2003). Restrictions on undocumented immigrants' access to health services: The public health implications of welfare reform. American Journal of Public Health, 93, 1630-1633.

Lesieur, H., \& Blume, S. (1987). The south oaks gambling screen (SOGS). A new instrument for identification of pathological gamblers. The American Journal of Psychiatry, 144(9), 1184-1188.

Loue, S., Faust, M., \& Bunce, A. (2000). The effect of immigration and welfare reform legislation on immigrants' access to health care, Cuyahoga, and Lorain counties. Journal of Immigrant Health, 2, 2330. doi:10.1023/A:1009535322184.

Loue, S., \& Mendez, N. (2005). Health and health access among urban immigrants. In S. Galea \& D. Vlahov (Eds.), Handbook of urban health: Populations, methods, and practice (pp. 103-126). New York: Springer-Verlag.

Marcelli, E. A., \& Lowell, B. L. (2005). Transnational twist: Pecuniary remittances and the socioeconomic integration of authorized and unauthorized Mexican immigrants in Los Angeles County. The International Migration Review, 39(1), 69-102.

Marin, G., Sabogal, F., Marin, B. V. O., Otero-Sabogal, R., \& Perez-Stable, E. J. (1987). Development of a short acculturation scale for Hispanics. Hispanic Journal of Behavioral Sciences, 9, 183-205. doi: 10.1177/07399863870092005.

Marshall, K. J., Urrutia-Rojas, X., Mas, F. S., \& Coggin, C. (2005). Health status and access to health care of documented and undocumented immigrant Latino women. Health Care for Women International, 26, 916-936. doi:10.1080/07399330500301846.

McCormick, R., Russo, A., Ramirez, L., \& Taber, J. (1984). Affective disorders among pathological gamblers seeking treatment. The American Journal of Psychiatry, 141, 215-218.

Murray, J. B. (1993). Review of research on pathological gambling. Psychological Reports, 72, 791-810.

Nandi, A., Galea, S., Lopez, G., Nandi, V., Strongarone, S., \& Ompad, D. C. (2008). Access to and use of health services among undocumented Mexican immigrants in a US Urban area. American Journal of Public Health, 98(2), 1-10.

Pantalon, M. V., Maciejewski, P. K., Desai, R., \& Potenza, M. N. (2008). Excitement- seeking gambling in a nationally representative sample of recreational gamblers. Journal of Gambling Studies, 24, 63-78. doi:10.1007/s10899-007-9075-3.

Passel, J. S. (2005, March). Estimates of the size and characteristics of the undocumented population. Available from the Pew Hispanic Center Web site, http://pewhispanic.org/resources/.

Potenza, M. N., Fiellin, D. A., Heninger, G. R., Rounsaville, B. J., \& Mazure, C. M. (2002). Gambling: An addictive behavior with health and primary care implications. Journal of General Internal Medicine, 17, 721-732. doi:10.1046/j.1525-1497.2002.10812.x.

Potenza, M. N., Maciejewski, P. K., \& Mazure, C. M. (2006a). A gender-based examination of part-year recreational gamblers. Journal of Gambling Studies, 22(1), 41-64. doi:10.1007/s10899-005-9002-4.

Potenza, M. N., Steinberg, M. A., Wu, R., Rounsaville, B. J., \& O'Malley, S. S. (2006b). Characteristics of older adult problem gamblers calling a gambling helpline. Journal of Gambling Studies, 22, 241-254. doi:10.1007/s10899-006-9013-9.

Raylu, N., \& Oei, T. P. (2004). Role of culture in gambling and problem gambling. Clinical Psychology Review, 23, 1087-1114. doi:10.1016/j.cpr.2003.09.005.

Scherrer, J. F., Xian, H., Shah, K. R., Volberg, R., Slutske, W., \& Eisen, S. A. (2005). Effects of genes, environment, and lifetime co-occurring disorders on health related quality of life in problem and pathological gamblers. Archives of General Psychiatry, 62, 677-683. doi:10.1001/archpsyc.62.6.677. 
Sherbourne, C. D., \& Stewart, A. L. (1991). The MOS social support survey. Social Science \& Medicine, 32(6), 705-714. doi:10.1016/0277-9536(91)90150-B.

The Newest New Yorkers 2000 (2004, October). New York: New York City Department of Planning. Retrieved March 1, 2008, from http://www.nyc.gov/html/dcp/html/census/nny.shtml.

Thorson, J., Powell, F. C., \& Hilt, M. (1994). Epidemiology of gambling and depression in an adult sample. Psychological Reports, 74, 987-994.

Trevorrow, K., \& Moore, K. (1998). Association between loneliness, social isolation, and women's electronic gaming machine gambling. Journal of Gambling Studies, 14, 263-284. doi:10.1023/A: 1022057609568.

U.S. Census Bureau. (2003). The foreign born population: 2000. Washington, DC: US Census Bureau.

Vlahov, D., Anthony, J. C., Munoz, A., Margolick, J., Nelson, K. E., Celentano, D. D., et al. (1991). The ALIVE study, a longitudinal study of HIV-1 infection in intravenous drug users: Description of methods and characteristics of participants. NIDA Research Monograph, 109, 75-100.

Volberg, R. A. (1994). The prevalence and demographics of pathological gamblers: Implications for public health. American Journal of Public Health, 84(2), 237-241.

Volberg, R. A. (1996). Prevalence studies of problem gambling in the United States. Journal of Gambling Studies, 12(2), 111-128. doi:10.1007/BF01539169.

Volberg, R. A. (2001). Changes in gambling and problem gambling in Oregon: Results from a replication study, 1997-2000. Northampton, MA: Gemini Research Inc.

Volberg, R. A. (2003). Gambling and problem gambling in Arizona. Report to the Arizona Lottery. Gemini Research. Available from: URL: www.problemgambling.az.gov.

Wardman, D., El-Guebaly, N., \& Hodgins, D. (2001). Problem and pathological gambling in North American aboriginal populations: A review of the empirical literature. Journal of Gambling Studies, 17(2), 81-100. doi:10.1023/A:1016699628402.

Welte, J. W., Barnes, G. M., Wieczorek, W. F., \& Tidwell, M. (2004a). Gambling participation and pathology in the United States-A sociodemographic analysis using classification trees. Addictive Behaviors, 29, 983-989. doi:10.1016/j.addbeh.2004.02.047.

Welte, J. W., Barnes, G. M., Wieczorek, W. G., Tidwell, M., \& Parker, J. (2002). Gambling participation in the U.S.-Results from a national survey. Journal of Gambling Studies, 18(4), 313-337. doi: 10.1023/A:1021019915591.

Welte, J. W., Barnes, G. M., Wieczorek, W. F., Tidwell, M., \& Parker, J. (2004b). Risk factors for pathological gambling. Addictive Behaviors, 29, 323-335. doi:10.1016/j.addbeh.2003.08.007.

Westermeyer, J., Canive, J., Garrard, J., Thuras, P., \& Thompson, J. (2005). Lifetime prevalence of pathological gambling among American Indian and Hispanic American veterans. American Journal of Public Health, 95(5), 860-866. doi:10.2105/AJPH.2003.023770. 